\title{
Investigating the Impact of Tilt Angle, Orientation, and Configuration on PV System Performance Using PVSyst Software
}

\author{
Saad A. Tuama, Omar A. Abdulrazzaq*, Shaima K. Abdulridha, Noora Faiq \\ Renewable Energy and Environment Research Center, Corporation of Research and Industrial Development, \\ Ministry of Industry and Minerals, Iraq
}

\section{Article information}

\section{Article history:}

Received: June, 24, 2021

Accepted: September, 17, 2021

Available online: September, 18, 2021

\section{Keywords:}

PVSyst program,

PV system design,

PV orientation,

Tilt angle

*Corresponding Author:

Omar A. Abdulrazzaq

omarsatar2003@gmail.com

\begin{abstract}
This paper introduces a comprehensive investigation on the performance of on-grid 2.7kWp residential scale PV system in Baghdad location with aid of PVSyst software simulation. The study focused on the impact of a wide range of PV tilt angles, orientations, and various configurations on the productivity of the system. Such comprehensive study was never investigated in literature over Baghdad city before, up to our knowledge. In this simulation, azimuth angle is varied from $-90^{\circ}$ to $90^{\circ}$ with a constant $30^{\circ}$ tilt angle, then tilt angle varied from $0^{\circ}$ to $90^{\circ}$ with a constant $0^{\circ}$ azimuth angle. Results revealed that the $30^{\circ}$ tilt angle with $0^{\circ}$ azimuth angle is giving the best PV performance among all other angles. It is also shown that small change in azimuth (up to $30^{\circ}$ ) has unnoticeable effect on the PV performance. The study concluded that small offset in azimuth is considered acceptable from the design side of view. It is also noticed that small tilt angles boost the productivity in summer months, while large tilts boost the productivity in winter months. But the optimum angle that gives the highest productivity over the whole year is $30^{\circ}$. These results are explained by the sun latitude throughout the months of the year. In addition, 2-seasons method configuration showed a better performance compared to all of the fixed configurations with an increase in energy production of $\sim 5 \%$. However, the best performance was obtained with the tracking configuration with energy production of $25 \%$ more than all of other configurations.
\end{abstract}

\section{Introduction}

The rapid escalating in the photovoltaic (PV) systems installation in the last few years is attributed to three factors: (i) the atmospheric pollution due to the use of fossil fuel, (ii) the efficiency improvement of the PV modules, (iii) the huge markdown in the PV modules price, and (iv) the possibility of offering a solution in remote area [1]. In fact, PV systems are now the most feasible and viable systems of energy from the economical point of view, even when comparing them with the traditional sources of energy [2]. In addition, the environmental feasibility of using 
PV systems is now under the greatest interest. The energy payback time of PV modules is less than 4 years [3], whereas PV modules can operate for up to 30 years [4]. Therefore, the transition from fossil fuel energy to PV energy is going so fast in the last decade. PV systems are usually categorized into three segments of scale [5]: (1) residential scale with up to $10 \mathrm{kWp},(2)$ commercial scale with up to $1 \mathrm{MWp}$, and (3) utility scale with a capacity that reaches to the gigawatt scale.

In addition to the environmental factors (such as shade, dust, and temperature) [6], tilt angle and orientation of PV modules are the key factors to obtain the best performance. The values of these factors are relevant to the location of the installation site [7]. Usually, PV modules have to be oriented towards the geographic south (also called true south) for all locations above the equator, while modules have to be oriented towards the geographic north for all locations bellow the equator [8]. Modules at the equator are oriented upward towards the zenith. On the other hand, the tilt angle of the modules is determined based on the latitude of the installation area in a way that assures that modules are facing the sun as much time as possible. Table 1 tabulates the optimal tilt angle for each month at Baghdad location with PV facing south (azimuth =0) [9]. The table displays a non-tracking system. When tracking system is used, azimuth and latitude should be considered, since they are changing daily and hourly all over the year as shown in Figure 1 [9].

Table 1: Optimum tilt angle of PV Panel for each month at Baghdad location [9].

\begin{tabular}{|c|c|c|c|c|c|c|c|c|c|c|c|c|c|}
\cline { 2 - 7 } \multicolumn{1}{c|}{} & Jan & Feb & Mar & Apr & May & Jun & Jul & Aug & Sep & Oct & Nov & Dec & Ave. \\
\hline $\begin{array}{c}\text { Optimal } \\
\text { Angle }\end{array}$ & $49^{\circ}$ & $41^{\circ}$ & $33^{\circ}$ & $25^{\circ}$ & $17^{\circ}$ & $10^{\circ}$ & $17^{\circ}$ & $25^{\circ}$ & $33^{\circ}$ & $41^{\circ}$ & $49^{\circ}$ & $56^{\circ}$ & $33^{\circ}$ \\
\hline
\end{tabular}

Tracking system (modules track the sun disk) is achieving the best PV performance. However, tracking systems add cost and complexity to the PV system and most designers avoid them. Hence, 4-seasons system, 2-seasons system, or fixed angle system are more common. Moreover, the installation of PV systems is restrained by the installation site circumstances and sometimes by the shapeliness. Some sites such as tall buildings with relatively small roofs (e.g. skyscrapers), façade configuration has to be the best option. Another example is parking garage, where PV modules are installed at a semi-flat angle to be more decorated. With all these and more complexities, the design will be complicated and sophisticated. Such designs with all of the mentioned variants have never been introduced over Baghdad city in a one study. This motivated us to introduce such comprehensive investigation. Considering the complexities in those variants, the use of PV designing tools is required. A variety of PV design tools are available these days [10]. One of the common and efficient tools is the PVSyst software [11-16]. The software is available online for a one-month trial version and a prepaid version as well [17]. PVSyst is an intuitive tool dedicated for PV design and simulation. The aim of this work is to utilize PVSyst software to design an ongrid $2.7 \mathrm{kWp}$ residential scale PV system with a wide variety of tilt angles and orientations over the city of Baghdad, in order to get better understanding of the effect of tilt and azimuth angles on the size and performance of PV system at the allocated site. 

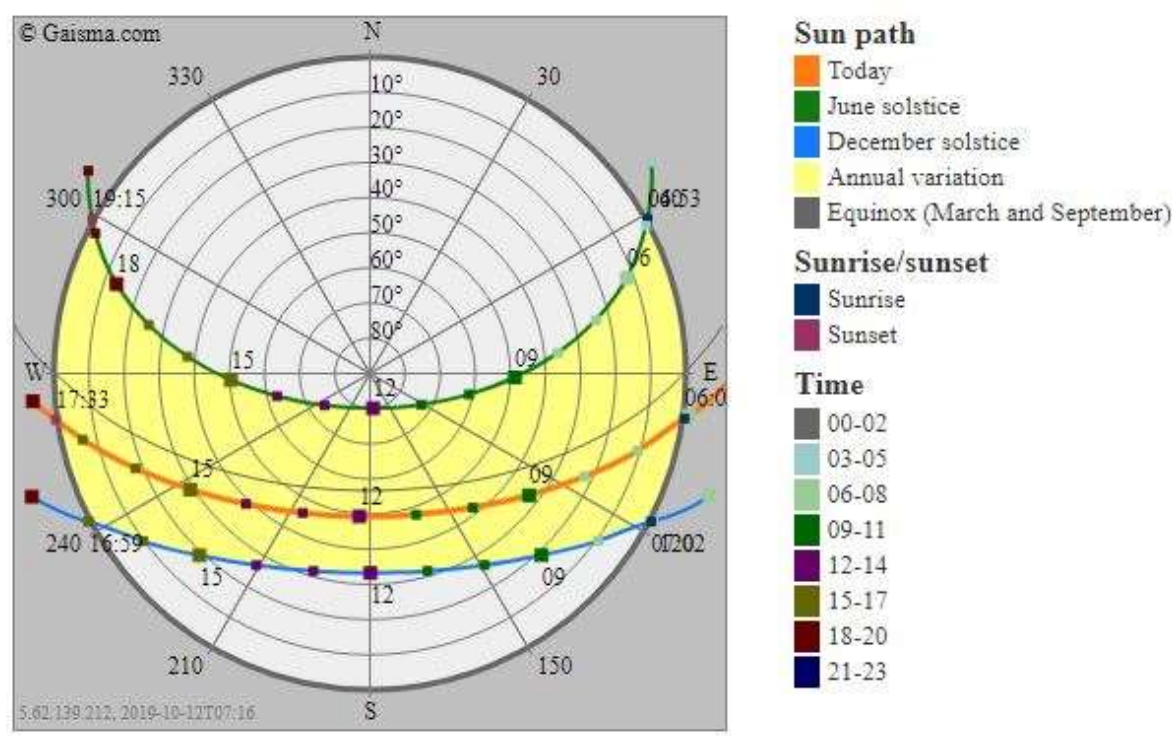

Figure 1: Sun path over Baghdad city throughout the year.

\section{Geographical and Meteorological Data}

The simulation of this work was pulled off in Baghdad - Iraq at Jadriyah location with coordinates of $33.28^{\circ} \mathrm{N}$ latitude and $44.39^{\circ} \mathrm{E}$ longitude. The altitude of this location is $33 \mathrm{~m}$ above sea level. Albedo was roughly estimated to be 0.2. Average temperatures (the average between highest and lowest temperature) for each month at this location are listed in Table 2.

Table 2: Average temperatures for each month at Baghdad location [17].

\begin{tabular}{|c|c|c|c|c|c|c|c|c|c|c|c|c|c|}
\cline { 2 - 10 } \multicolumn{1}{c|}{} & Jan & Feb & Mar & Apr & May & Jun & Jul & Aug & Sep & Oct & Nov & Dec & Ave. \\
\hline $\begin{array}{c}\text { Ave. Temp. } \\
\left({ }^{\circ} \mathrm{C}\right)\end{array}$ & 7.19 & 10.3 & 15.1 & 19.5 & 25.6 & 30.6 & 33.7 & 33.2 & 28 & 22.9 & 13.9 & 9.15 & 20.8 \\
\hline
\end{tabular}

\section{PV Array Characteristics}

\subsection{PV Modules Specifications}

The PV modules were picked out in this simulation from PVSyst software database. The chosen manufacturer and model are AEG, AS-M602G-300, respectively. The STC characteristics of the panel are shown in Table 3. Total number of PV modules is 9 with a total effective area of $14.9 \mathrm{~m}^{2}$.

Table 3: PV panel's parameters used in the simulation.

\begin{tabular}{|c|c|}
\hline Pm & $300 \mathrm{Wp}$ \\
\hline Im & $9.21 \mathrm{~A}$ \\
\hline Vm & $32.6 \mathrm{~V}$ \\
\hline Isc & $9.69 \mathrm{~A}$ \\
\hline Voc & $39.8 \mathrm{~V}$ \\
\hline FF & 0.779 \\
\hline Panel Eff. & $18.1 \%$ \\
\hline Dimensions & $1.66 \mathrm{~m}^{2}$ \\
\hline No. of Cells & 60 \\
\hline Pm Tem. Coeff. & $-0.39 \% /{ }^{\circ} \mathrm{C}$ \\
\hline Rs & $0.26 \Omega$ \\
\hline Rsh & $300 \Omega$ \\
\hline
\end{tabular}


The IV characteristics of the PV panel at various irradiance densities are presented in Figure 2. The figure shows a nearly linear increase in PV maximum power point with increasing irradiance. It is also shown that Isc significantly changes with irradiance whereas Voc exhibits a slight change. At $200 \mathrm{~W} / \mathrm{m}^{2}$ irradiance (corresponds to the early morning irradiance), PV panel produces around $20 \%$ of its nominal power, then power increases linearly with irradiance till $300.5 \mathrm{~W}$ at the $1000 \mathrm{~W} / \mathrm{m}^{2}$ AM1.5 illuminations. Temperature effect is neglected in these data and the values of this figure are determined at $25^{\circ} \mathrm{C}$. The output power may show a noticeable drop at higher temperatures as temperature coefficient for these modules is around $-0.39 \% /{ }^{\circ} \mathrm{C}$ as presented in Table 3 .

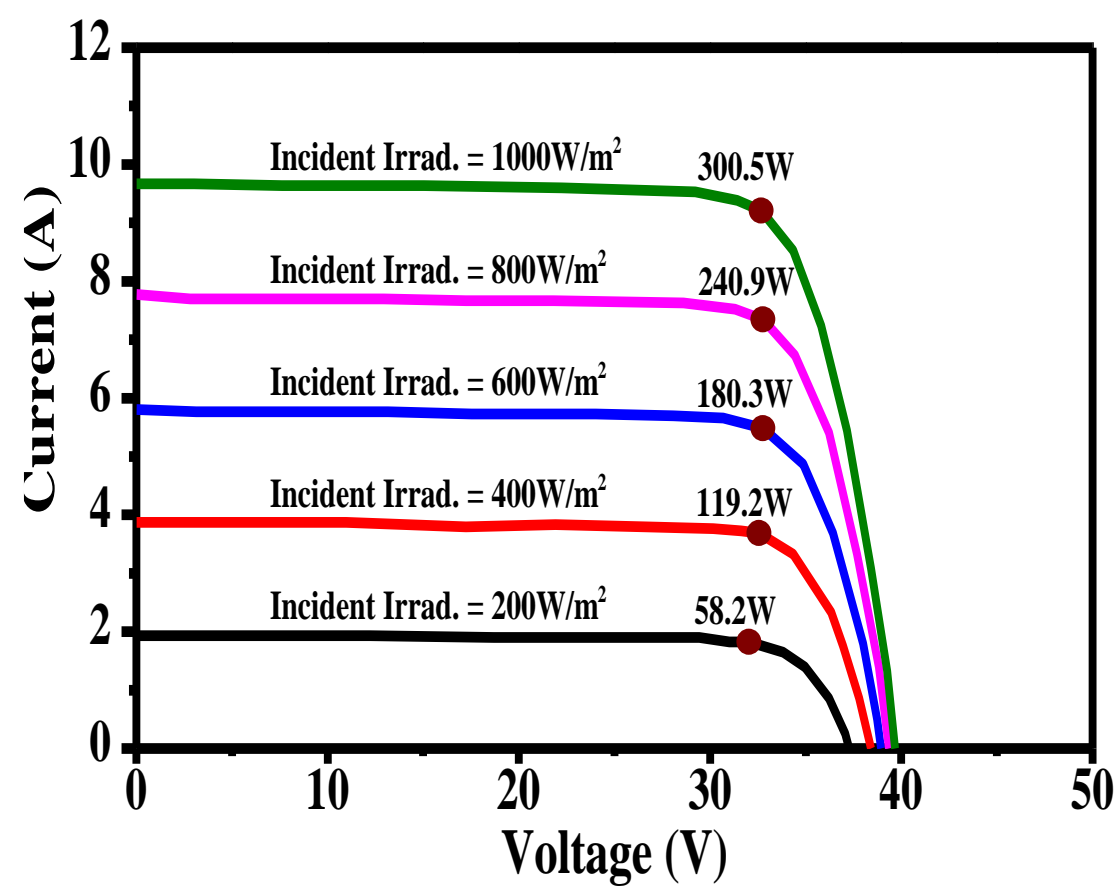

Figure 2: IV characteristics at various irradiance densities for PV panel used in the simulation.

\subsection{Inverter Specifications}

One inverter was used in the design of the system. The inverter manufacturer and model are SMA, Sunny Boy $3000 \mathrm{U}-240$, respectively. Table 4 lists the specifications of the inverter. The chosen inverter has a nominal output power of $3.2 \mathrm{~kW}$ which is slightly oversized and this is usually preferable by most of the PV array designers.

Table 4: Specifications of the inverter used in the simulation.

\begin{tabular}{|c|c|}
\hline Minimum MPPT Voltage & $200 \mathrm{~V}$ \\
\hline Maximum MPPT Voltage & $400 \mathrm{~V}$ \\
\hline Nominal DC Power & $3.2 \mathrm{~kW}$ \\
\hline Grid Voltage & $240 \mathrm{~V}(\mathrm{AC})$ \\
\hline Grid Frequency & $50 \mathrm{~Hz}$ \\
\hline Nominal AC Power & $3.0 \mathrm{~kW}$ \\
\hline Nominal AC Current & $12.5 \mathrm{~A}$ \\
\hline Maximum AC Current & $15 \mathrm{~A}$ \\
\hline Dimensions & $450 \times 352 \times 236 \mathrm{~mm}$ \\
\hline Weight & $40 \mathrm{~kg}$ \\
\hline Protection & $\mathrm{IP} 65$ \\
\hline Temp. Tolerance & -25 to $+45^{\circ} \mathrm{C}$ \\
\hline
\end{tabular}




\subsection{PV Array Loss Factors}

Array loss includes Joule's loss in the wires, efficiency drop due to temperature, maximum power point tracking loss, and light reflection on the surface. Those losses should be considered when designing a PV system to estimate the real energy delivered from the system. Table 5 lists those losses.

Table 5: Array loss factors from wires and panels.

\begin{tabular}{|l|l|}
\hline Wiring Ohmic Loss Fraction & $1.5 \%$ at STC \\
\hline Module Quality Loss Fraction & $-0.5 \%$ \\
\hline Module Mismatch Loss Fraction & $1 \%$ at MPP \\
\hline Strings Mismatch Loss Fraction & $0.1 \%$ \\
\hline Refractive Index of Antireflection Coating & 1.29 \\
\hline Refractive Index of Cover Glass & 1.526 \\
\hline
\end{tabular}

\section{Orientation, Tilting, and Nomenclature}

Various tilt angles and orientations were tested in this simulation as illustrated in Figure 3 to investigate the impact of these parameters on the productivity of the PV system if used over Baghdad city. The nomenclature of this study is denoted as follows:

1. $[\mathrm{T}(\mathrm{x}), \mathrm{A}(0)]$ : Azimuth angle (A) fixed at zero (south) and tilt angle $(\mathrm{T})$ varied from $\mathrm{T}=0^{\circ}$ for $[\mathrm{T}(0), \mathrm{A}(0)]$ to $\mathrm{T}=90^{\circ}$ for $[\mathrm{T}(90), \mathrm{A}(0)]$.

2. $[\mathrm{T}(30), \mathrm{A}(\mathrm{x})]$ : Tilt angle fixed at $30^{\circ}$ (the optimum tilt angle over Baghdad) and azimuth varied from $\mathrm{A}=10^{\circ}$ for $[\mathrm{T}(30), \mathrm{A}(10)]$ to $\mathrm{A}=90^{\circ}$ for $[\mathrm{T}(30), \mathrm{A}(90)]$.

3. $[\mathrm{T}(30), \mathrm{A}(-\mathrm{x})]$ : Tilt angle fixed at $30^{\circ}$ and azimuth varied from $\mathrm{A}=-10^{\circ}$ for $[\mathrm{T}(30), \mathrm{A}(-10)]$ to $\mathrm{A}=-90^{\circ}$ for $[\mathrm{T}(30), \mathrm{A}(-90)]$.

4. [Seasonal-T(13, 51), A(0)]: Panel is tilted at $13^{\circ}$ in summer and $51^{\circ}$ in winter.

5. [Facade-T(30), A(0)]: Tilt angle fixed at $30^{\circ}$ and azimuth fixed at zero. Three sheds (rows) were applied in the design.

6. [Carport-T(30), A(x, -x)]: Two panels oriented at two different directions with tilt angle fixed at $30^{\circ}$ and azimuth varied from $A=10$ for $[\mathrm{T}(30), \mathrm{A}(10)]$ to $\mathrm{A}=90^{\circ}$ for $[\mathrm{T}(30), \mathrm{A}(90)]$ for one panel and from $\mathrm{A}=-10^{\circ}$ for $[\mathrm{T}(30), \mathrm{A}(-10)]$ to $\mathrm{A}=-90^{\circ}$ for $[\mathrm{T}(30), \mathrm{A}(-90)]$ for the second panel.

7. [Tracker-T(x), A(x to $-\mathrm{x})]$ : Tracking is performed for tilt angle and azimuth. 


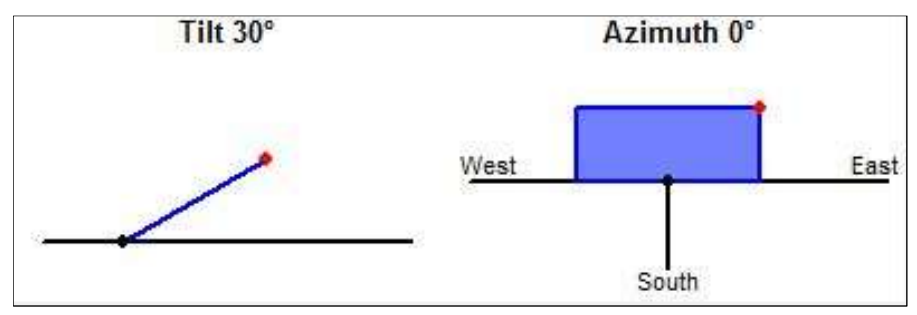

(a)

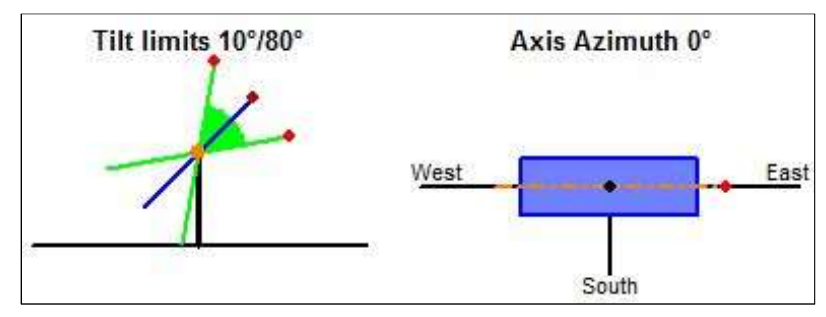

(b)
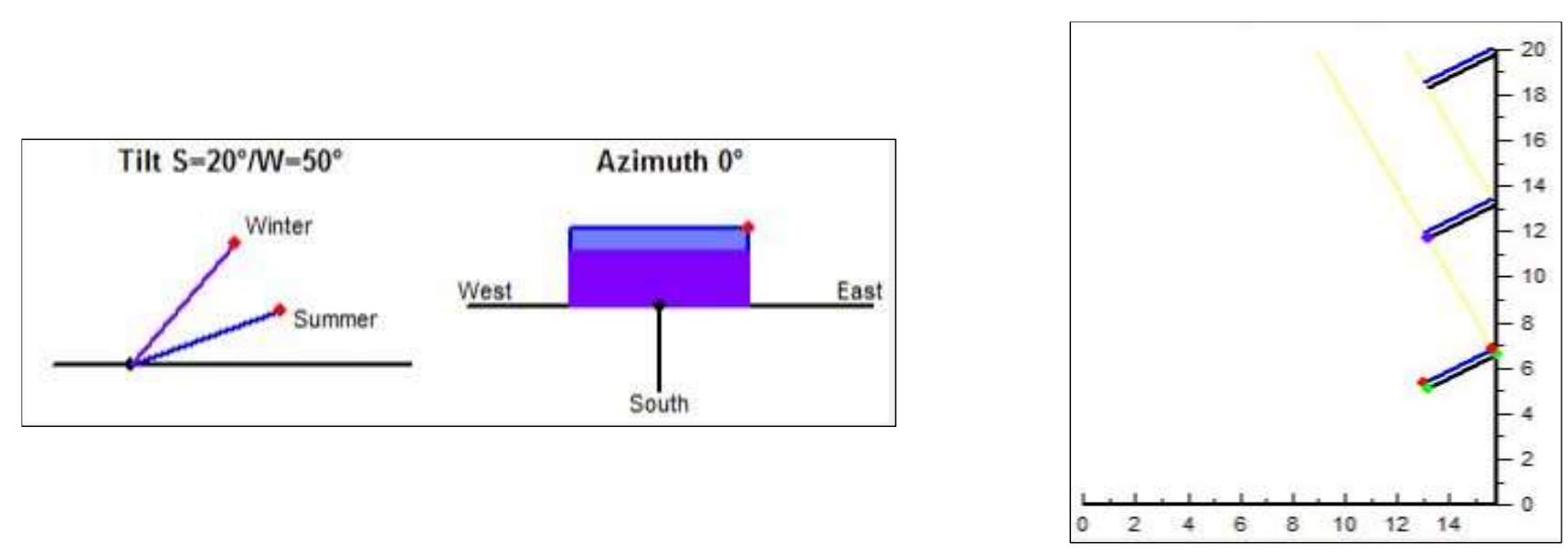

(c)

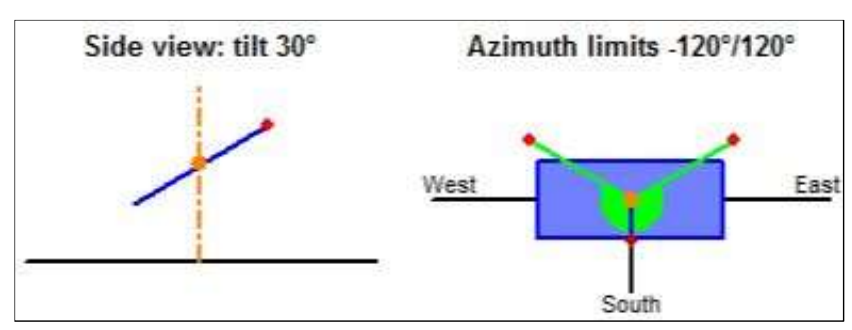

(e) (d)

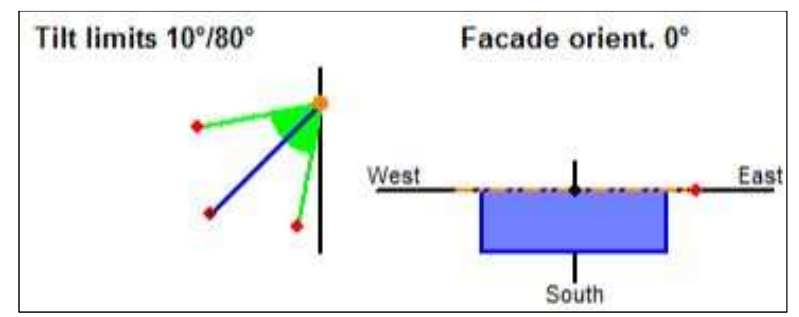

(f)

Figure 3: (a) tilt angle at $30^{\circ}$ and azimuth at zero, (b) constant azimuth with varied tilt angle, (c) seasonal configuration with tilt angle is changing twice a year, (d) façade configuration, (e) tracking system with constant tilt angle and varied azimuth from east to west, and (f) tracking system with varied azimuth and varied tilt angle.

\section{PVSyst Simulation Results and Discussion}

\section{1. $[\mathbf{T}(30), A( \pm x)]$ Configuration}

Figure 4 presents the influence of various azimuth angles on the system performance for PV modules fixed at $30^{\circ}$ tilt angle. Azimuth is varied from zero (facing south) to $90^{\circ}$ (facing west). Incident radiation (the energy of solar radiation per unit area that hits the surface in $\mathrm{kWh} / \mathrm{m}^{2}$ unit) depends on the angle of incident, which in turns depends on tilt angle, azimuth angle, time of the day, and month of the year. Highest received energy is obtained when the light beam hits the surface perpendicularly. Since sun path (the ecliptic on the celestial sphere) has different heights from the horizon during the hours of the day as shown earlier in Figure 1, the optimum azimuth angle that achieves the perpendicularity will be different for each hour during the daytime. Figure 4-a shows the amount of incident energy delivered to the panel's surface of PV system fixed at $30^{\circ}$ tilt angle and azimuth angle varied from zero (facing south) to $90^{\circ}$ (facing west). As seen from the figure, best energy accumulation over the year is obtained for [T(30), A(0)] configuration. Array energy production and energy injected to the grid show highest performance at $[\mathrm{T}(30), \mathrm{A}(0)]$, as well. At azimuths of $10^{\circ}$ and $30^{\circ}$, performance is slightly changing which means small change in azimuth has unnoticeable effect on the system performance. Same findings were recorded when azimuth is changed towards the east (i.e. $-10^{\circ}$ and $-30^{\circ}$ ) as shown in Figure 5. This gives the designer a plenty of room to fix the PV azimuth over a range of $30^{\circ}$ to $-30^{\circ}$. On the other hand, a noticeable change in PV performance is recorded at higher azimuths $\left(60^{\circ},-60,90^{\circ}\right.$, and $\left.-90^{\circ}\right)$ as shown in Figures $4 \& 5$. Higher azimuths 
reduce the amount of light reaching the PV surface because PV will be facing the sun disk with less hours. The two extremes $\left(90^{\circ}\right.$ and $\left.-90^{\circ}\right)$ are facing sun in sunset and sunshine, respectively and will be in offset at the rest of the day. For instance: At zero azimuth (facing south) and $30^{\circ}$ tilt angle, the total accumulated incident radiation per one squared meter over a year is $2021.9 \mathrm{kWh}$. Considering a total module area of $14.9 \mathrm{~m}^{2}$, the accumulated radiation through the year is $30126 \mathrm{kWh}$. This corresponds to a generated energy of $4682.8 \mathrm{kWh}$ and a grid injected energy of $4476.7 \mathrm{kWh}$. This gives an array efficiency of $15.5 \%$ (less than the module efficiency), and DC-to-AC inverting efficiency of $95.5 \%$. On the other hand, the total accumulated incident radiation per one squared meter over a year for $\mathrm{PV}$ at $90^{\circ}$ of azimuth (facing west) is $1709 \mathrm{kWh}$ and a total incident of $25464 \mathrm{kWh}$ over the array. This corresponds to a generated energy of $3935.9 \mathrm{kWh}$ and an injected energy of $3748.5 \mathrm{kWh}$, which gives the same array efficiency but a $16 \%$ less total generated energy, and DC-to-AC inverting efficiency of $95.2 \%$. Negative azimuths (towards east) are very much close to the positive azimuths and this is because the solar path is symmetric before and after noon. The small differences are attributed to the effect of differences in the ambient temperatures for a before-noon hours and its corresponding afternoon hours.

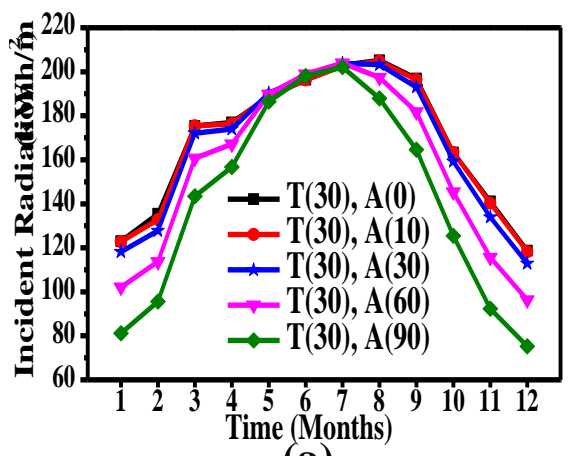

(a)

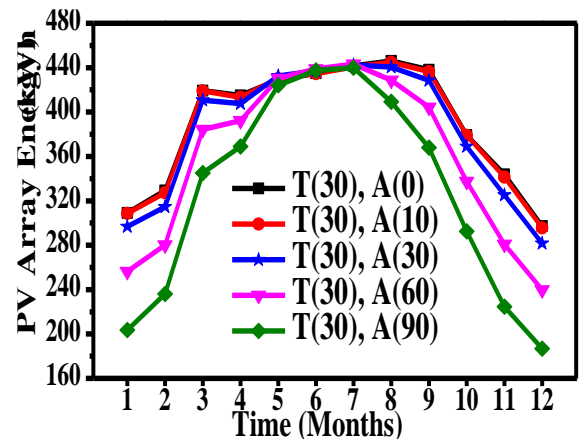

(b)

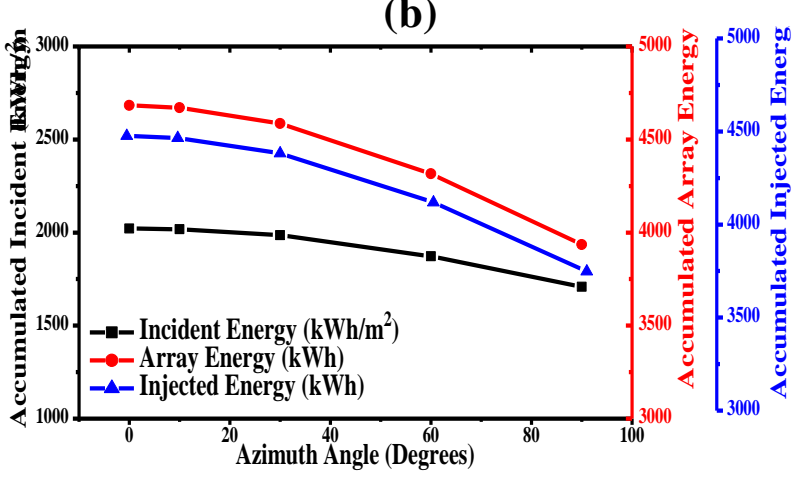

(d)

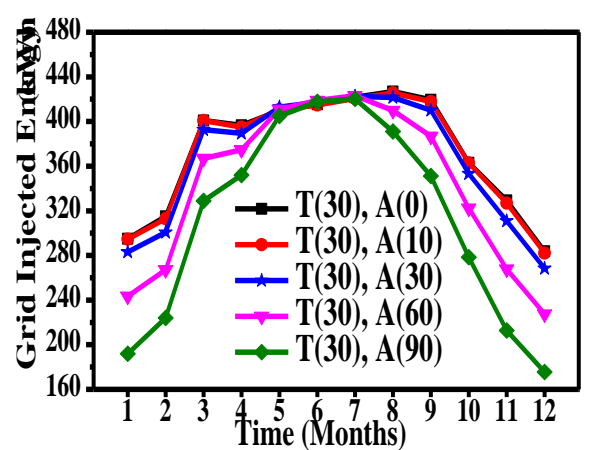

(c)

Figure 4: $[\mathrm{T}(30), \mathrm{A}(\mathrm{x})]$ configuration: (a) incident radiation received by the module surface, (b) generated energy by the array, (c) energy injected to the grid, and (d) accumulated incident, generated, and injected energies over one year. 


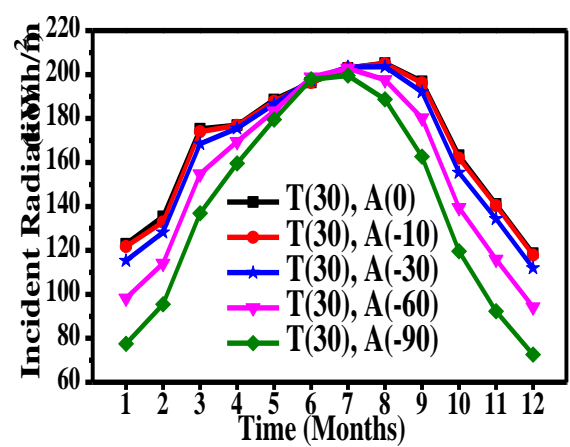

(a)

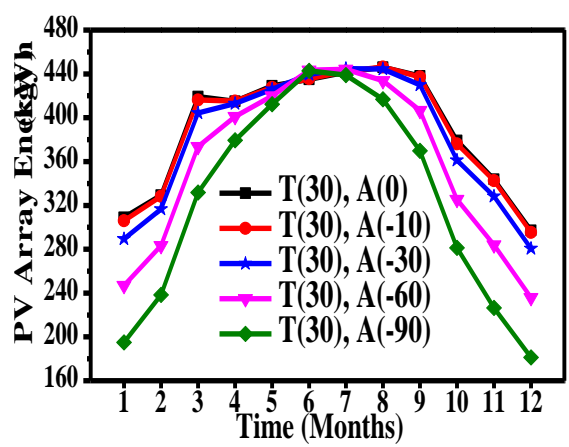

(b)
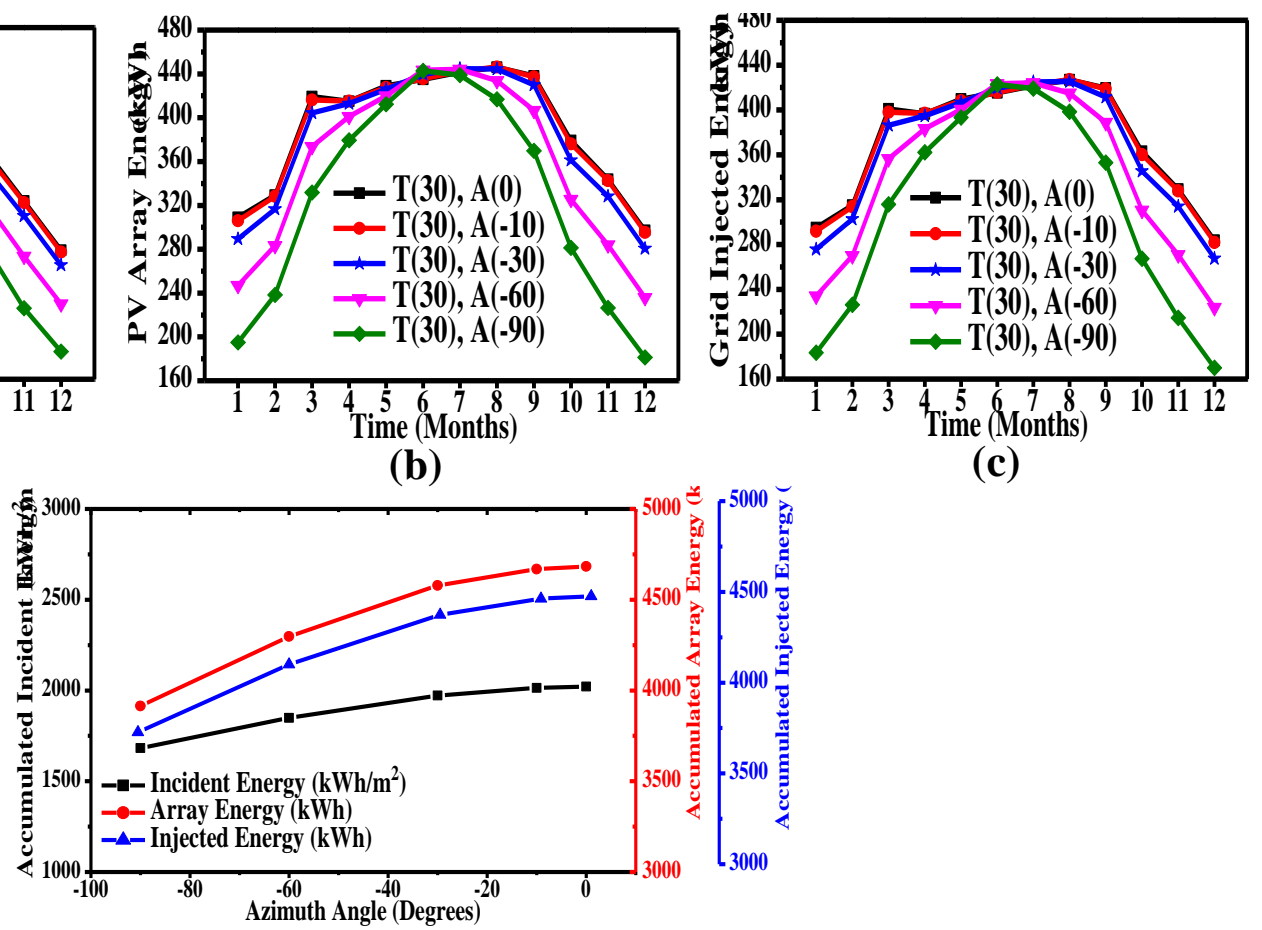

(c)

(d)

Figure 5: [T(30), A(-x)] configuration: (a) incident radiation received by the module surface, (b) generated energy by the array, (c) energy injected to the grid, and (d) accumulated incident, generated, and injected energies over one year.

\section{2. $[\mathbf{T}(\mathbf{x}), \mathbf{A}(0)]$ Configuration}

Figure 6 presents the influence of tilt angle on various PV parameters for PV modules oriented to the south (azimuth $=0$ ). Tilt angle varied from zero (horizontal angle) to $90^{\circ}$ (vertical angle). Figure $6-\mathrm{a}, \mathrm{b}, \& \mathrm{c}$ shows incident energy on the PV surface, generated energy by the PV array, and injected energy to the grid, respectively of PV system oriented to the south with tilt angles varied from zero and $90^{\circ}$. As seen from the figure, best generated energy accumulation by the array and accumulated injected energy to the grid over one year are obtained for [T(30), A(0)] simulation, which are similar to the results of Figures $(4 \& 5)$. At tilt angle of zero, best performance is obtained in summer months but it drops down in winter months and this is because ecliptic is on its highest in summer (summer solstice), so it faces the PV surface at this horizontal angle. The $60^{\circ}$ tilt angle is best in winter months but it drops down in summer months because ecliptic is on its lowest in winter, therefore, the perpendicularity is occurred at around $60^{\circ}$ tilt angle (the winter angle in Baghdad location). The $90^{\circ}$ tilt angle shows poor performance for most months, except for winter because sun path gets low in winter (winter solstice), so it faces the PV surface at this vertical angle. The two extremes $\left(0^{\circ} \& 90^{\circ}\right)$ are not recommended in Baghdad. Even though, horizontal tilt angle is recommended on the equator and vertical tilt angle is recommended on the pole. 


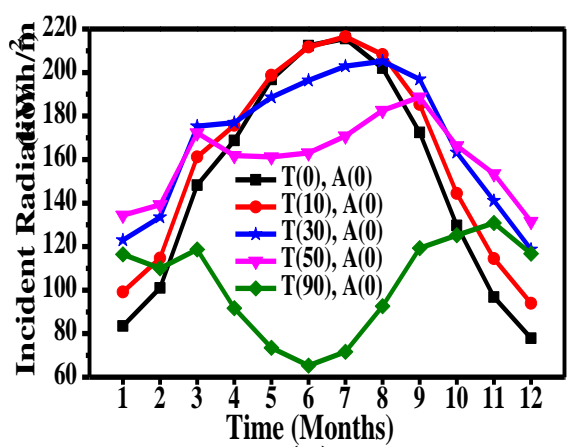

(a)

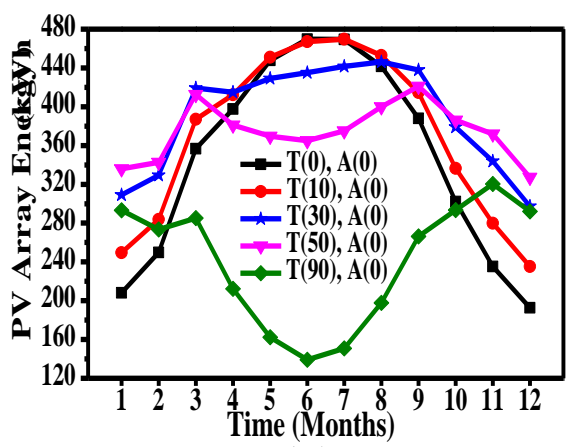

(b)
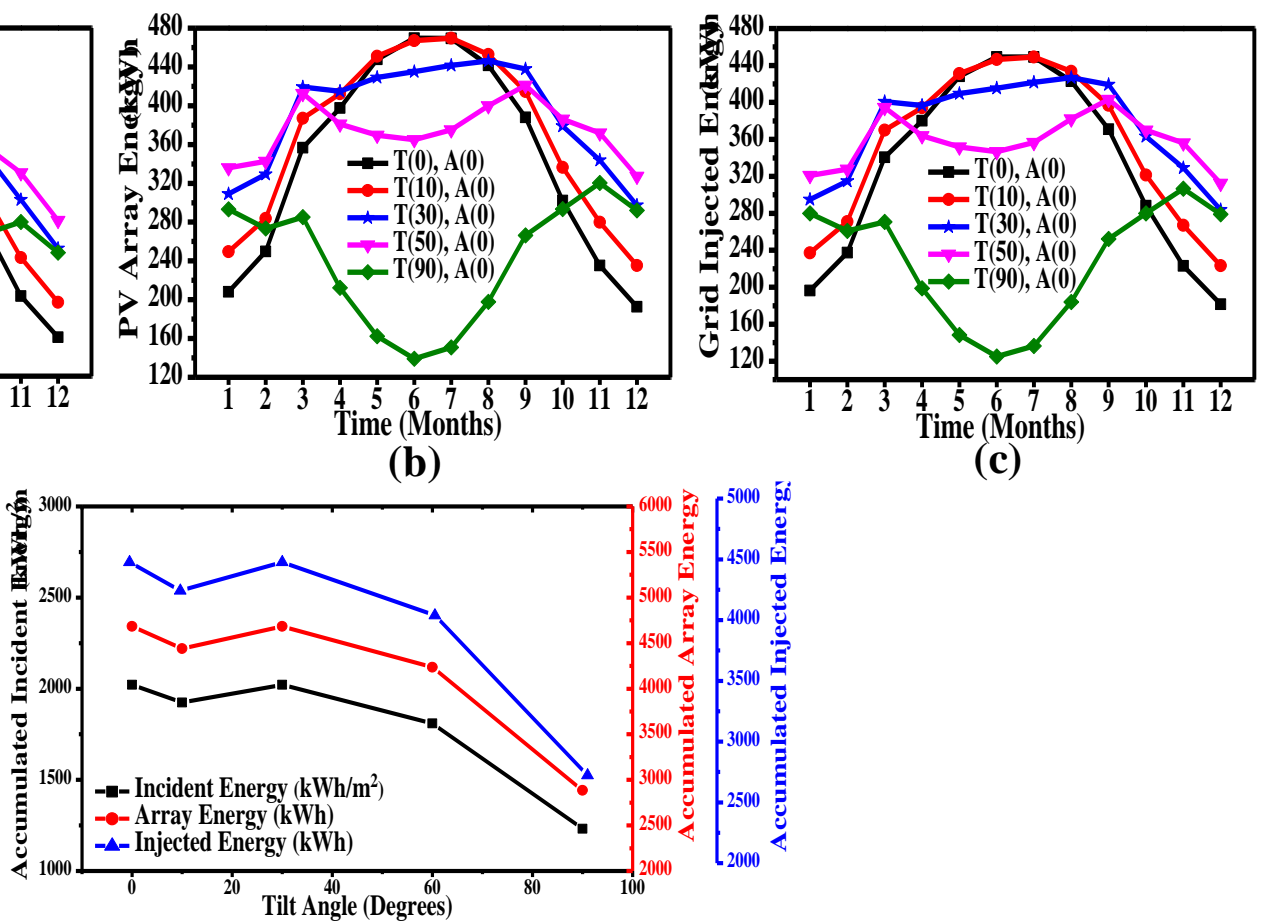

(c)

(d)

Figure 6: $[\mathrm{T}(\mathrm{x}), \mathrm{A}(0)]$ configuration: (a) incident radiation received by the module surface, (b) generated energy by the array, (c) energy injected to the grid, and (d) accumulated incident, generated, and injected energies over one year.

\section{3. [Facade-T(30), A(0)] Configuration}

Façade orientation is fixing the PV modules on the exterior frontage of a building. South face is preferable in this orientation. This design is used in some cases when there is no enough room for installing PV system on the roof or around the facility terrace. It can also add a decoration to the building from the architecting standpoint. Panels usually are fixed above the windows to act as window sunshade as well as a source of energy. In this configuration, the 9 panels are grouped into 3 sheds with 3 modules each and connected in series all together. Sheds spacing is fixed to be $6.6 \mathrm{~m}$. Figure 7 exhibits the PV parameters of such orientation where tilt angle fixed at $30^{\circ}$ and azimuth at zero. Since the simulation is done for [T(30), A(0)] configuration, results were as same as in Figures $(4,5, \& 6)$ for the similar configuration. The two shoulders appear in the equinoxes (March and September) are ascribed to the fact that $30^{\circ}$ tilt angle of this orientation is as same as the optimal angle of these two months described elsewhere in Table 1. Therefore, the equinox gives boost of energy in this orientation.

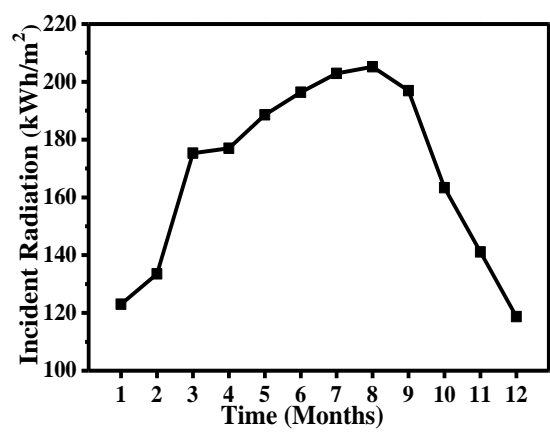

(a)

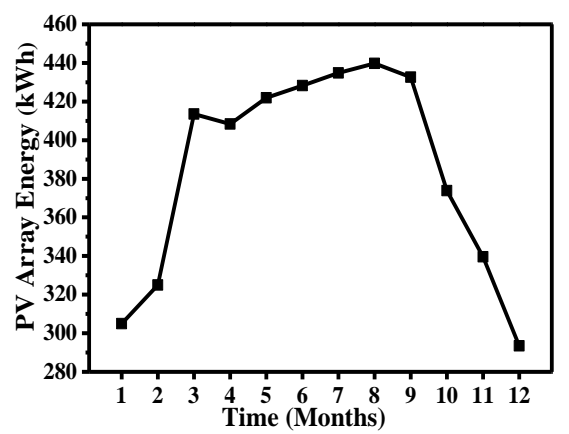

(b)

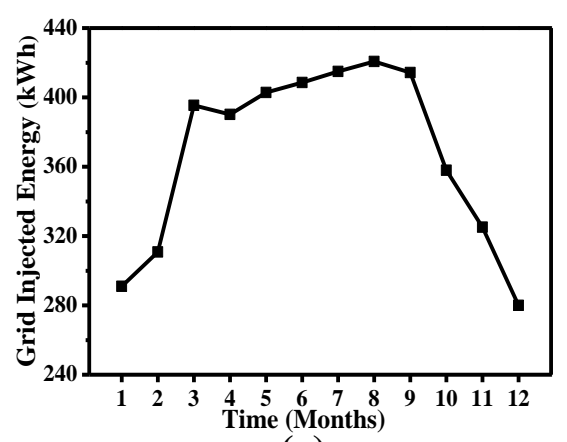

(c)

Figure 7: [Facade-T(30), A(0)] Configuration: (a) incident radiation received by the module surface, (b) generated energy by the array, and (c) energy injected to the grid. 


\section{4. [Seasonal-T(13, 51), A(0)] Configuration}

Since the optimum tilt angle is varied month to month, adjustable panel's frame is suitable to enhance the productivity of the PV system. Commonly, two-season configuration is preferable in PV system design, because it only requires a two adjustable hinges in the panel's frame. In this configuration, the simulation was performed on two tilting angles (a $13^{\circ}$ summer tilt and a $51^{\circ}$ winter tilt). This configuration assures a better performance than the fixed configuration because PV will be facing the sun as much as possible. The output of the PV system is shown in Figure 8. The figure shows an enhancement in the output energy during winter months and summer months (e.g. array energy is $336.5 \mathrm{kWh}$ in January and $467.9 \mathrm{kWh}$ in July compared to $309.1 \mathrm{kWh}$ in January and $441.6 \mathrm{kWh}$ in July for the [T(30), A(0)] configuration). In contrast, energy in spring and fall months is less (e.g. array energy is $411.4 \mathrm{kWh}$ in March compared to $419.2 \mathrm{kWh}$ in March for the [T(30), $\mathrm{A}(0)]$ configuration). However, the overall performance is better as will be discussed later on.

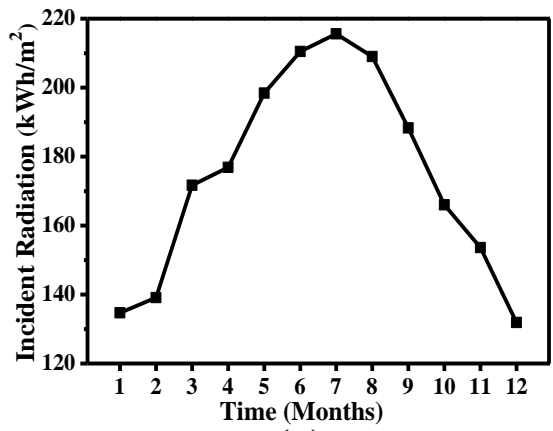

(a)

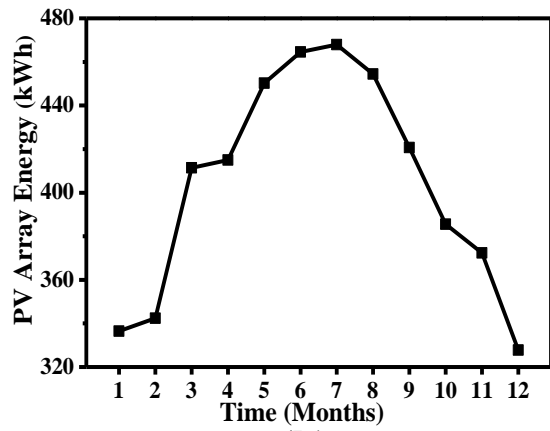

(b)

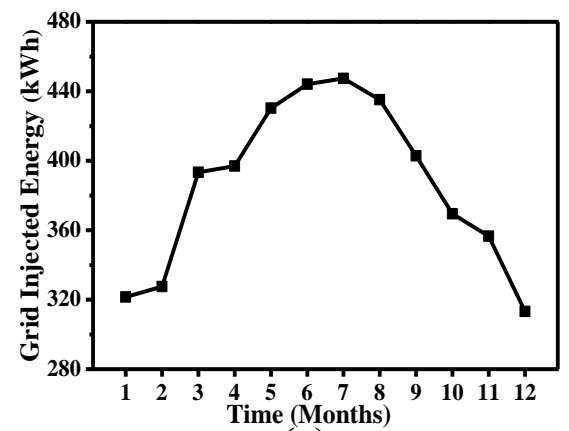

(c)

Figure 8: [Seasonal-T(13, 51), A(0)] Configuration: (a) incident radiation received by the module surface, (b) generated energy by the array, and (c) energy injected to the grid.

\section{5. [Carport-T(30), A(x, -x)] Configuration}

Carport configuration is usually used in parks as a shelter for vehicles and as a source of energy as well. The preferable configuration is a $30^{\circ}$ tilt angle with two sets of azimuth angle; one towards east and other towards west. Figure 9 demonstrates the PV parameters of such configuration. As azimuth increased the productivity of the system decreased. The lowest energy produced is for [T(30), A(90, -90)], particularly in winter months. However, this configuration is more convenient in term of architecture design. The [T(30), $\mathrm{A}(10,-10)]$ is unsuitable as a carport, especially with $30^{\circ}$ tilt angle.

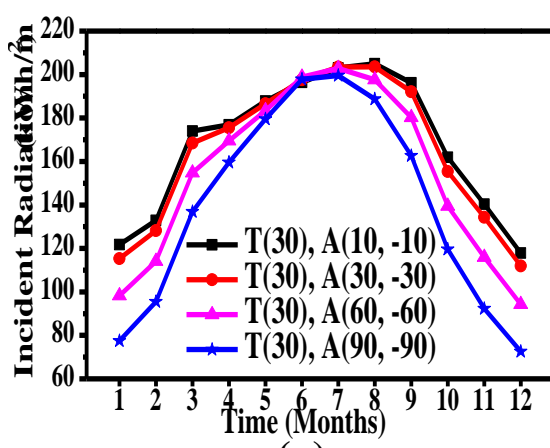

(a)

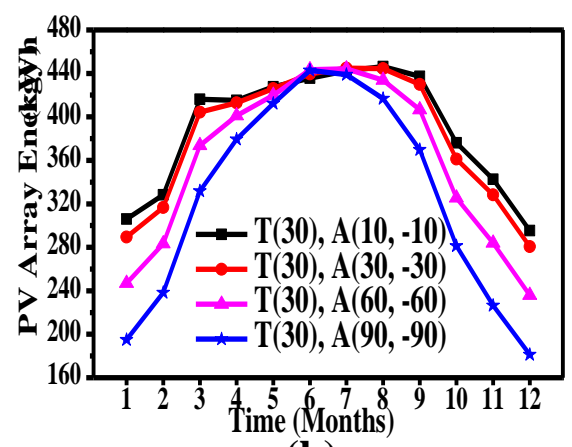

(b)

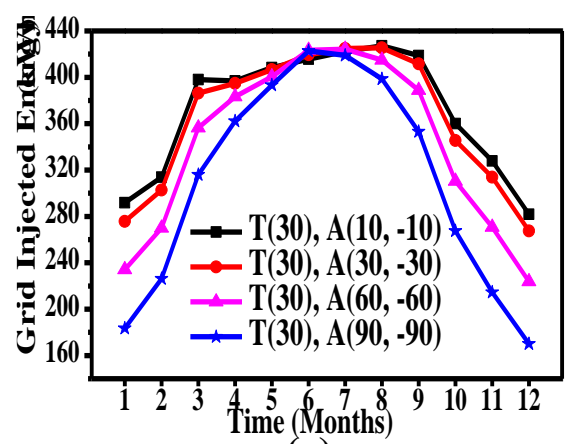

(c)

Figure 9: [Carport- $\mathrm{T}(30), \mathrm{A}(\mathrm{x},-\mathrm{x})$ ] Configuration: (a) incident radiation received by the module surface, (b) generated energy by the array, and (c) energy injected to the grid.

\section{6. [Tracker-T(x), A(x, -x)] Configuration}

Tracking system gives the best productivity compared to any other configuration. However, designers avoid this design in most cases because of the additional cost added to the system from using this design. Some cases when installation area is limited and high power is required, designers perform tracking system. Figure 10 depicts the performance of this system with two types of tracking: altitude tracking starting from the winter angle $\left(13^{\circ}\right)$ all the way to summer angle $\left(51^{\circ}\right)$ with constant azimuth $\left(\mathrm{A}=0^{\circ}\right)$, and azimuth tracking from $60^{\circ}$ to $-60^{\circ}$ with constant 
altitude $\left(\mathrm{T}=30^{\circ}\right)$. The figure shows that altitude tracking introduces better performance in summer months, whereas azimuth tracking introduces better performance in winter months. The accumulated energy produced by the array is $5844 \mathrm{kWh}$ for altitude tracking and $5507 \mathrm{kWh}$ for azimuth tracking. Therefore, the superiority is for altitude tracking.

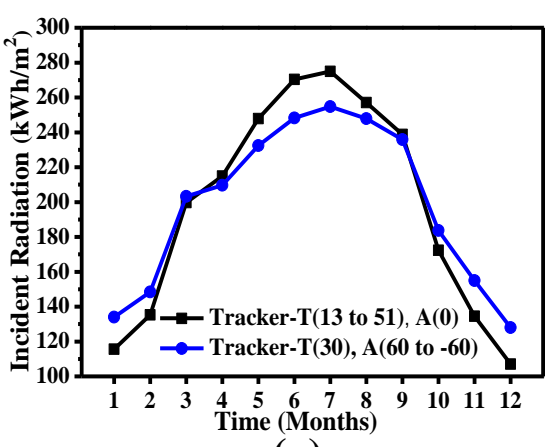

(a)

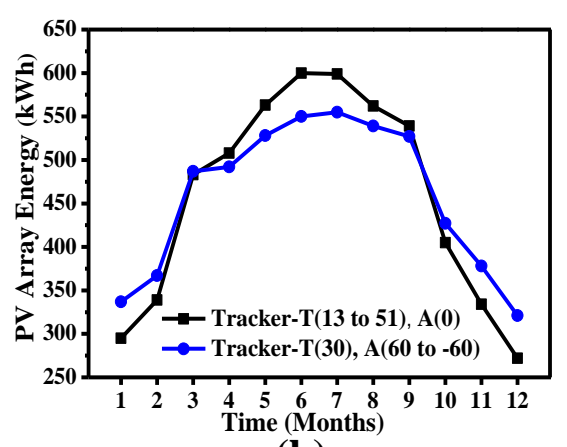

(b)

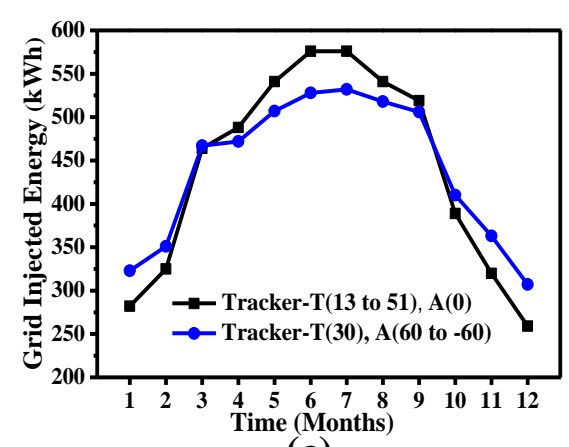

(c)

Figure 10: [Tracker-T(x), $A(x,-x)$ ] Configuration: (a) incident radiation received by the module surface, (b) generated energy by the array, and (c) energy injected to the grid.

\section{Comparison Discussion}

The total generated energy from the PV system in one year for a set of configurations is illustrated in Figure 11. It is obvious from the figure that [T(30), $\mathrm{A}(0)],[\mathrm{T}(30), \mathrm{A}( \pm 10)]$, [Façade], and [Carport] generate nearly equal amount of annual energy with a highest value for [T(30), A(0)]. Practically, designer can choose any of those configurations with no significant loss of energy if design circumstances require. In addition, seasonal configuration gives higher energy with $\sim 5 \%$ more energy than $[\mathrm{T}(30), \mathrm{A}(0)]$ configuration. But anyhow, the 2seasons method requires adjusting the tilt angle manually twice a year (namely in April, 30 and September, 12), which is a tedious job, especially with large scale PV systems. The tracking configuration exhibits the highest energy generation with a $25 \%$ extra energy compared to [T(30), A(0)] configuration for an example. However, the tracking system adds up a significant cost to the system and requires more maintenance services.

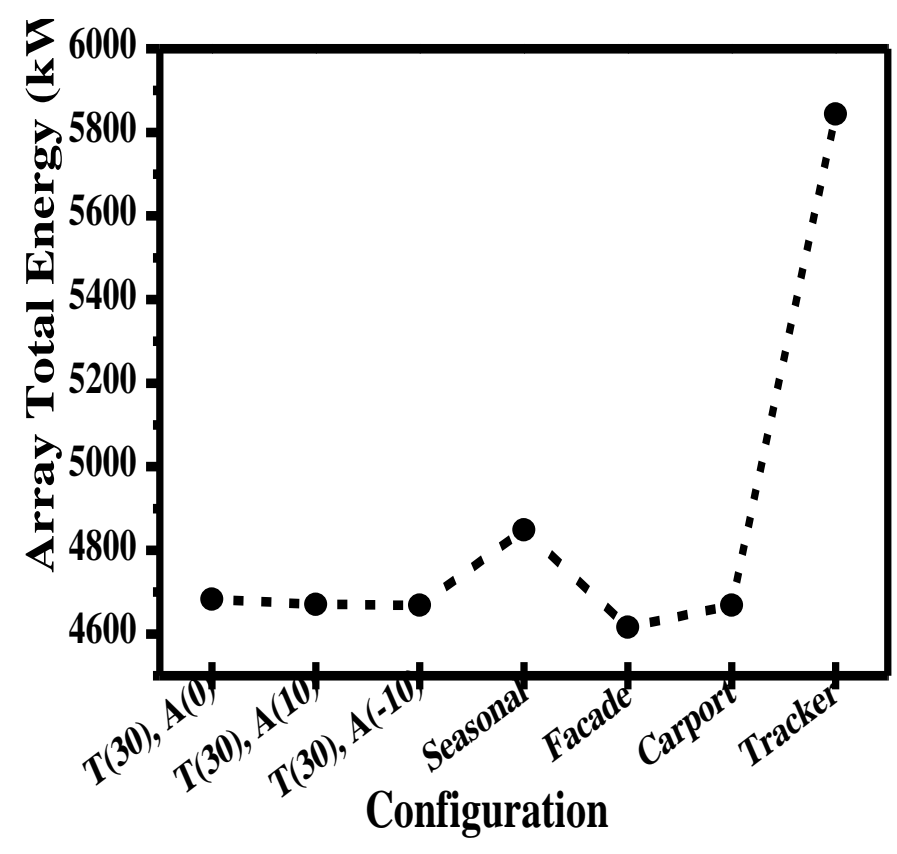

Figure 11: Total energy generated by the array throughout a year for some chosen configurations used in this study. 


\section{Environment Feasibility}

Carbon balance is one of the main benefits of using photovoltaics. Carbon dioxide $\left(\mathrm{CO}_{2}\right)$ emission equivalent is calculated by PVSyst software with a grid lifecycle emission of $0.869 \mathrm{kgCO}_{2} / \mathrm{kWh}$. The lifetime of PV system is assumed to be 30 years with an annual degradation of $1 \%$. Accordingly, $\mathrm{CO}_{2}$ replaced emission is calculated as portrayed in Figure 12. The figure shows the [T(30), A(0)] configuration as an example. Total emission balance in 30 years is 96.1 tons of $\mathrm{CO}_{2}$. Energy payback time is defined as: "the length of time required for photovoltaic solar modules to generate an amount of energy equal to the energy used for manufacturing them" [18]. Generally speaking, monocrystalline silicon has longer payback time than polycrystalline, while thin film solar cells have the least payback time [19]. However, for a certain type of solar cell, the used manufacturing technology pinpoints the payback time of it. Roughly, silicon PV modules have a payback time somewhere between 1 and 4 years [3]. PVSyst software estimated the payback time of the PV panel (model AS-M602G-300) used in this simulation to be 1.3 years with manufacturing emission for 9 modules of around 4 tons of $\mathrm{CO}_{2}\left(0.44\right.$ ton of $\mathrm{CO}_{2}$ per one module) as shown in Figure 12.

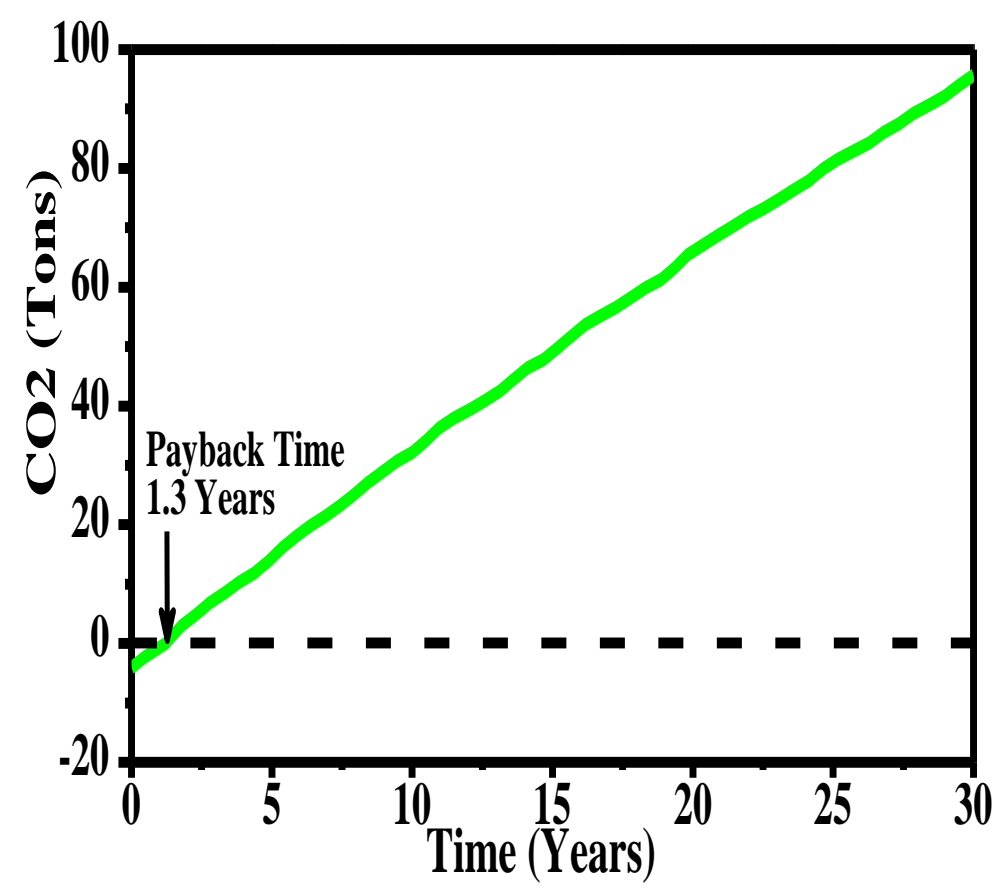

Figure 12: Carbon dioxide saving for $[\mathrm{T}(30, \mathrm{~A}(0)]$ configuration over a span of 30 years.

\section{Conclusions}

From the above simulation results, it can be deduced that the best tilt and azimuth angles in Baghdad city are $30^{\circ}$ and $0^{\circ}$, respectively. The optimum configuration [T(30), A(0)] ensures a low Energy Payback Time of only 1.3 years. The $30^{\circ}$ tilt angle is close to the latitude of Baghdad location, which shows that latitude value can be used as a reference to choose the optimum tilting in any location. Azimuth of $0^{\circ}$ (geographic south) is the optimum value for any location above the equator. A small change in azimuth has no obvious effect on the PV performance. Therefore, designing systems with azimuth variation from $30^{\circ}$ to $-30^{\circ}$ is accepted within reason. Although tracking configuration is the best choice for the highest performance, the complexity associated with this design makes it a secondary choice. Seasonal configuration can be a choice when seeking for high energy output. Carport configuration is used as park shelter. Although the carport configuration produces less power, it can be more convenient in terms of architecture design, available area, and cost considerations. 


\section{Acknowledgement}

Financial and logistic support from the Renewable Energy and Environment Research Center at the Corporation of Research and Industrial Development are greatly appreciated.

\section{Conflict of Interest}

The authors declare that they have no conflict of interest.

\section{References}

[1]A. Zahedi, "Solar photovoltaic (PV) energy; latest developments in the building integrated and hybrid PV systems," Renew. Energy, vol. 31pp. 711-718, 2006.

[2] A. H. Salloom, O. A. Abdulrazzaq, B. H. Ismail, and A. D. Salman, "Ground Effect on the Performance of Back-to-back Stacked Silicon Solar Panel System: An Imitation for a Bifacial Solar Panel," Iraqi J. Ind. Res., vol. 6, pp. 8-15, 2019.

[3] K. P. Bhandari, J. M. Collier, R. J. Ellingson, and D. S. Apul, "Energy payback time (EPBT) and energy return on energy invested (EROI) of solar photovoltaic systems: A systematic review and meta-analysis," Renew. Sustain. Energy Rev., vol. 47, pp. 133-141, 2015.

[4] W. Luo et al., "A comparative life-cycle assessment of photovoltaic electricity generation in Singapore by multicrystalline silicon technologies," Sol. Energy Mater. Sol. Cells, vol. 174, pp. 157-162, 2018.

[5]A. Goodrich, T. James, and M. Woodhouse, "Residential, commercial, and utility-scale photovoltaic (PV) system prices in the United States: current drivers and cost-reduction opportunities," National Renewable Energy Lab. (NREL), Golden, CO (United States), 2012.

[6] S. K. Abdulridha, S. A. Tuma, and O. A. Abdulrazzaq, "Study of the Partial Shading Effect on the Performance of Silicon PV Panels String,” J. Appl. Sci. Nanotechnol., vol. 1, pp. 32-42, Apr. 2021.

[7] M. Hartner, A. Ortner, A. Hiesl, and R. Haas, "East to west - The optimal tilt angle and orientation of photovoltaic panels from an electricity system perspective," Appl. Energy, vol. 160, pp. 94-107, 2015.

[8] A. K. Yadav and S. S. Chandel, "Tilt angle optimization to maximize incident solar radiation: A review," Renew. Sustain. Energy Rev., vol. 23, pp. 503-513, 2013.

[9] Sunearthtools, "Tools for consumers and designers of solar," Sunearthtools.Com, 2014. [Online]. Available: http://www.sunearthtools.com/dp/tools/pos_sun.php. [Accessed: May, 2021].

[10 W. F. Holmgren, C. W. Hansen, J. S. Stein, and M. A. Mikofski, "Review of Open Source Tools for PV Modeling," in 2018 IEEE 7th World Conference on Photovoltaic Energy Conversion (WCPEC) (A Joint Conference of 45th IEEE PVSC, 28th PVSEC \& 34th EU PVSEC), pp. 2557-2560, 2018.

[11] N. M. Kumar, M. R. Kumar, P. R. Rejoice, and M. Mathew, "Performance analysis of $100 \mathrm{kWp}$ grid connected Si-poly photovoltaic system using PVsyst simulation tool," Energy Procedia, vol. 117, pp. 180-189, 2017.

[12] J. V Ramoliya, "Performance Evaluation of Grid-connected Solar Photovoltaic plant using PVSYST Software," JETIR1502036 J. Emerg. Technol. Innov. Res., vol. 2, pp. 372-378, 2015.

[13] R. Tallab and A. Malek, "Predict system efficiency of $1 \mathrm{MWc}$ photovoltaic power plant interconnected to the distribution network using PVSYST software," in 2015 3rd International Renewable and Sustainable Energy Conference (IRSEC), 2015, pp. 1-4.

[14] P. Yadav, N. Kumar, and S. S. Chandel, "Simulation and performance analysis of a $1 \mathrm{kWp}$ photovoltaic system using PVsyst," 4th IEEE Spons. Int. Conf. Comput. Power, Energy, Inf. Commun. ICCPEIC 2015, pp. 358363, 2015.

[15] C. P. Kandasamy, P. Prabu, and K. Niruba, "Solar potential assessment using PVSYST software," in 2013 International Conference on Green Computing, Communication and Conservation of Energy (ICGCE), 2013, pp. 667-672.

[16] Y. M. Irwan, A. R. Amelia, M. Irwanto, Fareq.M, W. Z. Leow, N. Gomesh, et al., "Stand-Alone Photovoltaic (SAPV) System Assessment using PVSYST Software," Energy Procedia, vol. 79, pp. 596-603, 2015.

[17] PVsyst, "PVsyst photovoltaic software," PVSyst, 2019. [Online]. Available: http://www.pvsyst.com/en/. [Accessed: May, 2021].

[18] K. Knapp and T. Jester, "Empirical investigation of the energy payback time for photovoltaic modules," Sol. Energy, vol. 71, pp. 165-172, 2001.

[19] K. L. Chopra, P. D. Paulson, and V. Dutta, "Thin-film solar cells: an overview," Prog. Photovoltaics Res. Appl., vol. 12, pp. 69-92, 2004. 